\title{
Science, advocacy, and quackery in nutritional books: an analysis of conflicting advice and purported claims of nutritional best-sellers
}

\author{
Rebecca M. Marton 1,2, Xindi Wang ${ }^{3}$, Albert-László Barabási ${ }^{3,4}$ \& John P.A. loannidis 2,5,6凶
}

\begin{abstract}
Nutritional decisions may be important for health, and yet identifying trustworthy sources of advice can be difficult to achieve. Many people turn to books for nutritional advice, making the contents of these books and the expertise of their authors relevant to public health. Here, the top 100 best-selling books were identified and assessed for both the claims they make in their summaries and the credentials of the authors. Weight loss was a common theme in the summaries of nutritional best-selling books. In addition to weight loss, 31 of the books promised to cure or prevent a host of diseases, including diabetes, heart disease, cancer, and dementia; however, the nutritional advice given to achieve these outcomes varied widely in terms of which types of foods should be consumed or avoided and this information was often contradictory between books. Recommendations regarding the consumption of carbohydrates, dairy, proteins, and fat in particular differed greatly between books. To determine the qualifications of each author in making nutritional claims, the highest earned degree and listed occupations of each author was researched and analyzed. Out of 83 unique authors, 33 had an M.D. or Ph.D degree. Twenty-eight of the authors were physicians, three were dietitians, and other authors held a wide range of jobs, including personal trainers, bloggers, and actors. Of 20 authors who had or claimed university affiliations, seven had a current university appointment that could be verified online in university directories. This study illuminates the range of the incongruous information being dispersed to the public and emphasizes the need for future efforts to improve the dissemination of sound nutritional advice.
\end{abstract}

\footnotetext{
${ }^{1}$ Institute for Stem Cell Biology and Regenerative Medicine, Stanford University Medical School, Stanford, CA 94305, USA. ${ }^{2}$ Meta-Research Innovation Center at Stanford (METRICS), Stanford University, Stanford, CA 94305, USA. ${ }^{3}$ Network Science Institute, Northeastern University, Boston, MA, USA.

${ }^{4}$ Division of Network Medicine, Department of Medicine, Harvard Medical School, Boston, MA, USA. ${ }^{5}$ Department of Medicine, Department of Epidemiology and Population Health, and Department of Biomedical Data Science, Stanford University School of Medicine, Stanford, CA 94305, USA.

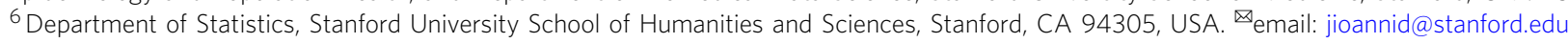




\section{Introduction}

dentifying the composition of the optimal diet for different individuals is a worthy and challenging enterprise for science and public health. However, reaching certainty on nutritional advice has been an elusive goal. US national guidelines are congressionally mandated to be updated every 5 years (U.S. Department of Health and Human Services and U.S. Department of Agriculture, 2015), but they often rely on contested evidence, and it has been suggested that major reform is needed in the field to obtain rigorous scientific evidence (Ioannidis, 2018). At the same time, nutrition is undoubtedly important and nutritional choices represent an everyday dilemma. While many individuals seek dietary advice, the same percentage of consumers report seeking nutritional information from family and friends as from healthcare professionals (30\%), and roughly the same percentage of consumers report seeking nutritional information from news articles or headlines, or news on TV as from a conversation with a registered dietitian or nutritionist (23-24\%) (Internation Food Information Council Foundation, 2018). Misinformed nutritional beliefs once formed can become pervasive (Casazza et al., 2013). In order to understand the magnitude of this problem, we evaluated the educational and occupational credentials of best-selling authors to determine the extent to which they have training and experience in health and nutritional sciences. As the credentials of the authors do not necessarily indicate the quality of the nutritional advice given, we also assessed the distribution of nutritional advice and purported health benefits contained in summaries of these best-selling books.

\section{Methods}

We used data from best-sellers on nutritional advice. To identify best-sellers, we used data capturing of sales patterns for bestsellers and their authors (Yucesoy et al., 2018). Here, we focused on the best-selling books in the category of "Health and Fitness", which includes books related to health, fitness, and medicine that are aimed at nonprofessionals. The books were screened by extracting summaries from Google Books and assessing whether each book contained nutritional advice and was primarily focused on food. Almost half of the best sellers on Health and Fitness are primarily about nutrition advice. The proportion would be greater if one were to include culinary recipe books and books that touch upon nutrition along with other topics. By ranking the books in decreasing sales during the period 2008-2015 (Yucesoy et al., 2018), we identified 100 nutrition-focused books among the top-227, after excluding 47 books that were on pregnancy, exercise, beauty, and fashion; 8 recipe or reference books that did not contain nutritional advice; and 59 that touched on multiple themes (one of which might have been nutrition and diet, but not exclusively so). Moreover, 12 nutrition books had appeared in two or more editions in the top-selling list, and we counted only the top-selling edition. Overall, these top 100 nutrition-focused best-sellers had sales ranging from 23,228 to 730,901 (median 55,735).

For each author, we attempted to extract educational and occupational information by searching their name in online searches to find biographies, interviews and news articles, including the author's occupational information. These searches were performed between 15 October, 2018 and 27 October, 2018. We also utilized Wikipedia pages and Google Books author information when possible. We performed additional searches in Google Scholar for the authors that claimed to have university faculty appointments and recorded the number and type of publications with 100 or more citations, such as research articles, reviews, or opinion pieces. Only a minority of published works reach 100 citations, therefore passing this threshold can signify substantial visibility of the published work. We also validated claims of faculty appointment by searching for the author in the corresponding university's faculty listing. These searches were performed between 1 November, 2018 and 22 November, 2018.

From each summary provided by Google Books, we extracted information on the length of time in days of the recommended nutritional plans, the suggested amount of weight loss in pounds, whether the book claimed to increase lifespan or energy levels, and whether the book purported to help cure or prevent disease. If so, we also recorded the specific diseases claimed to be prevented or cured in the book summary. We additionally recorded the key nutritional recommendations given in each book summary, such as the suggested type of diet or the specific classes of foods that should be consumed or avoided.

We also conducted a text-mining analysis of the full text of seven of the ten best-selling books to determine whether the terms "systematic review", "meta-analysis", and "randomiz(s)ed" in the setting of controlled/clinical trials were used. Three of the top ten best-selling books were excluded from this analysis, as they were not available in electronic form.

\section{Results}

Author qualifications. There were 83 unique authors among the top 100 diet and nutrition-focused books as some authors had multiple best-seller hits among the top 100. Additionally, two books had no single attributed individual author and are listed as being a collective edition. Of the 83 authors, $33.7 \%$ had a medical degree and $6.0 \%$ had a Ph.D degree, while about half of the authors had no M.D., Ph.D or other graduate degree (see Fig. 1a). The current and previous occupations of the authors revealed that a Author Education

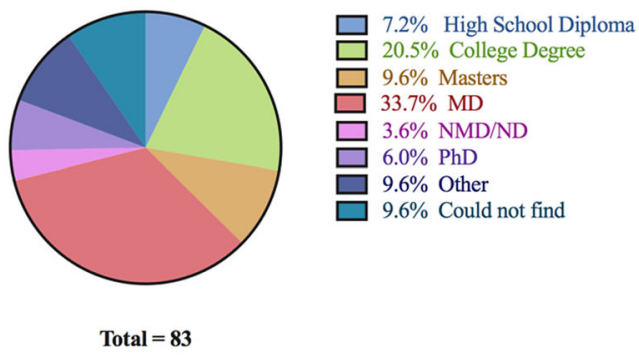

b Author Occupation

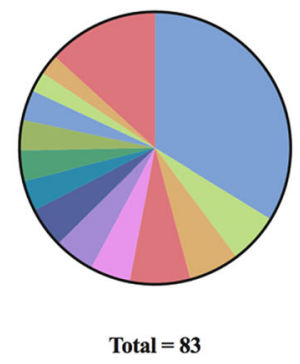

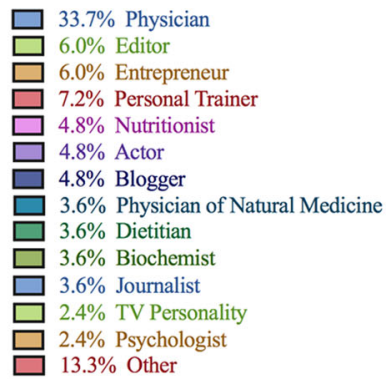

Fig. 1 Education and occupations of best-selling authors. The highest levels of educational attainment (a) and the occupations (b) of the 83 best-selling authors based on available information. The most common highest degree was a medical degree and the most common occupation was physician. M.D. Doctor of Medicine, N.M.D./N.D. Doctor of Naturopathic Medicine, Ph.D Doctor of Philosophy. 
a third of them were at some point practicing physicians, and a great variety of other occupations were also represented, including editors, entrepreneurs, personal trainers, nutritionists, actors, bloggers, reality television stars, a fire fighter, and a professional pool player (see Fig. 1b).

Purported health benefits. We collected and categorized the Google Books summary of each of the top 100 diet and nutritionrelated books. Eighty of the summaries mentioned weight loss or weight management, and of the summaries that specified a program length and/or the number of pounds that could be lost, the median was 21 days $(n=45$, interquartile range (IQR) 14-30) and 15.5 pounds $(n=20$, IQR $10-20)$, respectively. Apart from weight loss, one of the most common claims of the summaries was that the nutritional and diet advice in the books could cure or prevent disease $(n=31)$. The most commonly listed diseases were diabetes $(n=15)$ and heart disease $(n=12)$. Other commonly listed diseases that could be treated or prevented using these books were cancer $(n=11)$, dementia $(n=8)$, arthritis $(n=6)$, autoimmune disorders $(n=5)$, Parkinson's disease $(n=3)$, autism spectrum disorder $(n=3)$, and depression $(n=3)$. Two additional common claims in the summaries were that following the advice in the book could increase energy levels $(n=13)$ and lifespan $(n=7)$.

Incongruent nutritional recommendations. The 100 summaries of best-selling books showed very little consistency in terms of what were the key components of diet that would achieve all these benefits. Many summaries included strong views surrounding the consumption of carbohydrates, as six summaries suggested a low or no carb diet and six suggest being gluten or grain free. However, four summaries did support eating grains or bread and one suggested a high-carb diet. Other summaries disagreed about the consumption of dairy, as two summaries insisted that dairy products should not be consumed, while three claimed that dairy products should be consumed. Of those that suggested that dairy products should be consumed, two said that non or low-fat dairy products are preferable, and one said full fat dairy products are preferable. Summaries also included differing views on which food groups should be emphasized in one's diet, as nine summaries suggested a high-plant diet, seven suggested a high-fat diet, and four suggested a high-protein diet. Several summaries promoted popular diets, including four summaries that suggested a Mediterranean diet, three that supported a paleo diet, and two promoted a ketogenic diet. Other summaries promoted replacing meals altogether, as five mentioned replacing meals with smoothies and two suggested replacing meals with bone broth. Three summaries suggested alternating dieting strategies to confuse or boost one's metabolism. A number of additional nutritional suggestions were made in the summaries, including eating anti-inflammatory foods $(n=3)$, reducing processed foods $(n=6)$, reducing or replacing sugar consumption $(n=8)$, eating nutrient dense foods $(n=3)$, eating a vegetarian diet, $(n=3)$, eating whole foods $(n=5)$, and eating foods with a low glycemic index $(n=2)$.

There was lack of consensus on some simple issues, e.g., whether calories are important and should be counted. Based on the book summaries, one summary suggested counting calories, while eight books advised their readers not to count calories. One summary suggested reducing portions/calories, four advised not to reduce portions/calories, three suggested cycling size of portions/calories consumed, and two encouraged their readers to eat more food. Given the large, almost wild, diversity in nutritional opinions and claims, it may be difficult to set a threshold of what would qualify as disputable and unsubsantiated versus not. Regardless, many claims seemed very puzzling to us and based on our knowledge of the scientific literature we would not be able to even remotely endorse them. Same examples appear in Box 1.

\section{Box 1. I A sample of claims that appear disputable and/or unsubstantiated according to our expertize and opinion}

1. "Carbs are destroying your brain"-Grain Brain

2. "Have high blood pressure? Hibiscus tea can work better than a leading hypertensive drug-and without the side effects. Fighting off liver disease? Drinking coffee can reduce liver inflammation. Battling breast cancer? Consuming soy is associated with prolonged survival."-How Not to Die

3. "Zero Belly diet attacks fat on a genetic level, placing a bull's-eye on the fat cells that matter most: visceral fat, the type of fat ensconced in your belly."-Zero Belly Diet

4. "SKIP THE CRUNCHES: They just build muscle under the fat...LESS (EXERCISE) IS MORE"-This Is Why You're Fat (And How to Get Thin Forever)

5. "Eating pasta, bread, potato, and pizza will actually make you happier, healthier, and thinner-for good"-The Carb Lovers Diet

6. "Skip breakfast, stop counting calories, eat high levels of healthy saturated fat, work out and sleep less, and add smart supplements"-The

Bulletproof Diet

7. "Modern "improvements" to our food supply-including refrigeration, sanitation, and modified grains-have damaged our intestinal health. Dr. Axe offers simple ways to get these needed microbes, from incorporating local honey and bee pollen into your diet to forgoing hand sanitizers and even ingesting a little probiotic-rich soil"-Eat Dirt

8. "Overeating doesn't make you fat; the process of getting fat makes you overeat."-Always Hungry?

9. "Do you have an overall sense of not feeling your best, but it has been going on so long it's actually normal to you? You may have an autoimmune disease, and this book is the "medicine" you need."-The Immune System Recovery Plan

10. "Shows you how to grow new receptors for your seven metabolic hormones, making you lose weight and feel great fast!"-The Hormone Reset Diet 11. "The world's foremost expert on the therapeutic use of culinary spices, takes an in-depth look at 50 different spices and their curative qualities, and offers spice "prescriptions"-categorized by health condition-to match the right spice to a specific ailment."-Healing Spices

12. "The idea that people simply eat too much is no longer supported by science"-The Adrenal Reset Diet

13. "Most of us think God is not concerned with what we eat, but the Bible actually offers great insight and instruction about the effects of food on our bodies"-Let Food Be Your Medicine

14. "Dieters can actually lose weight by eating foods, nutrients, teas, and spices that change the chemical balance of the brain for permanent weight loss - a major factor contributing to how quickly the body ages. In fact, everyone can take years off their age by changing their brain chemistry." - Younger (Thinner) You Diet

15. "Weight gain is not about the food, but about the body's environment. Excess weight is a result of the body being in a toxic, inflammatory state. If your body is not prepared or 'primed' for weight loss, you will fight an uphill biochemical battle"-The Prime

16. "Throwing ice cubes in your water to make it more "structured". Skipping breakfast, as it could be making you fat. Eating up to 75 percent of your calories each day in fat for optimal health, reduction of heart disease, and cancer prevention"-Effortless Healing 
Authors with university appointments. We decided to further investigate the credentials of these best-selling authors to see how many of them had faculty appointments in universities. Of the 83 authors, we found a total of 20 authors with some mention of a faculty appointment, either currently or in the past. Of those 20, seven were currently on the faculty of some university and the information could be validated in the website of the institution by searching their name. Several of these authors seemed to have auxiliary appointments at adjunct or "voluntary" positions (unclear what that latter faculty title means). Most of the current professors were in biomedical (including nutrition-related) fields, but one was on the faculty of non-fiction writing. Fifteen authors with some identified or claimed faculty appointment had at least one publication with 100 or more citations as first or last authors in Google Scholar (often opinion pieces rather than full research papers and papers with data).

We also more thoroughly evaluated the profile, career and claims of the 20 authors associated with universities. University-affiliated authors are embedded by definition in academic environments where scientific publications, as well as scrutiny of the publications and research practices may be expected.

One author (Aggarwal) had 28 of his papers retracted and another ten had expressions of concern while another 17 had corrections as of 9 January, 2020 due largely to the reuse of images in figures, e.g., see several references for discussion of these issues (Prasad et al., 2016a; Sung et al., 2016a; Kannappan et al., 2016; Sung et al., 2016b; Gupta et al., 2016; Prasad et al., 2016b; Ackerman, 2016). An updated list of papers with retractions, expressions of concern, and corrections along with full details on each of them can be found in the Retraction Watch database. ${ }^{1}$

We also noted that several other authors had attracted fierce criticism for some of their claims. For example, one author (Perlmutter) was listed by Quackwatch in a list of "Promoters of Questionable Methods and/or Advice". ${ }^{2}$ He has received severe criticism from scientists about his claims that Alzheimer's disease, depression, Parkinson's disease, and attention deficit hyperactivity disorder (ADHD) can be prevented by avoiding grains, or that the link between autism and vaccines is "ill-defined" (Levinovitz, 2015). Other scientists have made claims that some books made assertions that had no or little scientific foundation, as in the case of South Beach Diet proposed by Agatston (Goff et al., 2006) and Wheat Belly proposed by Davis (Brouns et al., 2013). We refer readers to the published criticisms where they can judge for themselves the validity of the original claims made in the books and the counterclaims and we encourage them to also take into account the original authors' potential rebuttals of any criticisms.

Finally, the enthusiasm of several of the authors about a new discipline of "functional medicine" was very controversial among some scientific circles but was enthusiastically endorsed by others. Even the definition of functional medicine is non-standardized and it includes different elements of holistic, alternative, and traditional medicine.

Text-mining of full books. To determine the extent to which nutritional claims were backed up with evidence from the scientific literature, the full text of seven of the ten best-selling were searched for the terms "systematic review", "meta-analysis" and "randomiz(s)ed" in the setting of controlled/clinical trials. One of the seven referenced meta-analyses of the nutritional literature ("The 20/20 Diet"), and three referenced randomized controlled or clinical trials ("Master Your Metabolism", "Flat Belly Diet!", and "The 20/20 Diet"), though only one of these referenced more than five ("The 20/20 Diet"). The majority of appearances of the search terms occurred in article names cited at the end of each book (25 out of 28). However, "Master Your Metabolism" and
“The 20/20 Diet" did not include in-text citations, making it difficult to tell where the information from the scientific articles was incorporated, and whether any claim made in the text corresponded to a specific study.

\section{Discussion}

Every day people face the decision of what to consume in order to fuel their bodies. These choices can have a large impact on overall health, and it is therefore logical that many people search for reliable nutritional information. Food and diet are part of a cultural identity and we know little about how exactly information, from books or other sources, influences cultural identities and choices. Nevertheless, it is uncontestable that many people's choices are influenced by best-selling nutritional and diet books. We assessed the top 100 best-selling books in health and nutrition to determine the credentials of the authors and the scope of nutritional recommendations they purvey in their summaries. We found that a third of authors had medical degrees and seven had confirmable university appointments. Author professions ranged from physicians and personal trainers to entrepreneurs and reality TV stars, and five of the authors faced legal or professional repercussions for the content of their books. In addition to promising weight loss, based on Google Book summaries at least 31 of the books also purported to prevent or treat disease, including diabetes, heart disease, cancer, and dementia. However, the nutritional recommendations within these books were extremely varied and often in direct conflict with one another.

In all, our assessment of the summaries of best-selling books on nutrition shows that they may provide information or misinformation about very important matters and they are a heterogeneous mix. We cannot exclude that some of them may be providing sound or even excellent advice, but it is likely that many, probably the large majority, contain substantial misinformation and claims that have no scientific foundation. Our assessment by text-mining seven top-selling books showed little reference to standard evidence-based medicine tools (randomized trials and meta-analyses). The information spread in these books may eventually have more impact on the public than the peer-reviewed scientific literature, as more consumers reported using nutritional information from friends and family members or from news articles or headlines or news on TV than from reading a scientific study in 2018 (Internation Food Information Council Foundation, 2018). Major flaws, conflicts, lack of proper author credentials and evasion of proper scientific documentation may need to be more broadly communicated to the public. Regulatory agencies such as the Food and Drug Administration have no clear framework for intervening at the moment. However, we need to find ways to safeguard the public from misinformation. Greater public awareness of the untrustworthiness of much of this literature is needed. In an era of escalating anti-science movements, the downfall of nutrition science and its compounded misrepresentation are also particularly dangerous for the reputation of science at large.

Notably, several of these authors seemed to have become wealthy entrepreneurs. The magnitude and types of potential financial incentives and potential conflicts need to be more visible, regardless of whether these books include highly problematic content, or they provide the most excellent and perfectly accurate advise one can read. A glimpse of the financial issues at stake and the magnitude of funds involved can be gleaned currently only in a fragmented manner mostly from incidental news coverage in the business world. For example, Agastson was listed as part owner of SBD Enterprises LLC, owning the "South Beach Diet" trademark. Nutrisystem acquired the SBD brand for \$15 million in 2015 (Nutrisytem, 2015). The SBD brand was projected to earn $\$ 66$ to $\$ 70$ million in 2018 through sales of its meal programs, 
products, and services (Nutrisystem, 2018). Other authors are also selling products to accompany their diet books, including Haylie Pomroy's shakes, bars and cleanses and Pierre Dukan's diet foods and supplements. Even if all these books and their related initiatives represented outstanding contributions to public health, financial transparency would be helpful.

Most of the authors of these best sellers are not active in the peer-reviewed scientific literature. Among those who are publishing extensively in the peer-reviewed literature, we found one who was investigated for research fraud and then retired (Prasad et al., 2016a; Sung et al., 2016a; Kannappan et al., 2016; Sung et al., 2016b; Gupta et al., 2016; Prasad et al., 2016b; Ackerman, 2016). As we perused the available information of the careers of the authors of nutrition best-selling books, we also came across some examples of legal or regulatory repercussions. One author lost his ability to practice medicine and was investigated by the New York district attorney for promoting questionable health practices (Attorney General of the State of New York Health Care Bureau, 2014; Penketh, 2014), one received several letters of warning from the United States Food and Drug Administration (Walker, 2005; MacIntire, 2006), and one was convicted for misrepresenting the content of his books among other crimes and went to jail (Department of Justice, 2013). We want to avoid being judgmental, and we cannot exclude the possibility that the original authors may have appealed or have different takes on some of these legal or regulatory repercussions; nor do we want to take sides in any legal debate. However, these observations suggest that the field is rife with tension that may reach beyond the remit of literature and science.

A potential limitation of this study is that the analyses were performed on the content on the books' summaries and not on the book itself. It is unclear who writes the summaries that appear on Google Books, and to what extent they accurately reflect the promises and advice given within the text itself. We cannot exclude the possibility that the summaries are biased and that they selectively highlight some particular aspects but not others. However, we preferred to use this source, since it is widely used and is the basis for many consumers' decision to buy a given nutritional book. Additionally, we assessed the credentials of only the primary author identified for each book in our search, and it is possible that additional academic or nutritional experts are referenced within the text. Future studies may use qualitative methods to examine the full text of the top-selling nutritional books and this may offer additional insights besides the automated approach that we applied to screen for the presence of pivotal evidence-related words in a sample of full text books. It is possible that some nutrition-related books support their positions by other scientific arguments, or by less rigorous, and less scientifically based reasoning. Additional studies would also benefit from investigating alternative sources of nutritional advice, as information dissemination is shifting from print to other forms of media, including blogs and social media. With thousands of nutritional accounts promising to improve health and help with weight loss on social media sites, it is likely that an increasing proportion of the population will turn to these sources in the future. With no formal mechanisms in place to provide oversight or enforce accountability on these platforms, it is currently impossible to tell whether the quality of nutritional information reaching the public via these mechanisms will improve as more healthcare professionals develop a social media presence or worsen as unqualified sources gain an online audience.

\section{Data availability}

All data generated or analyzed during this study are included in supplementary tables associated with this published article.
Received: 16 April 2019; Accepted: 14 October 2019; Published online: 17 March 2020

\section{Notes}

1 Retraction Watch: http://retractiondatabase.org/RetractionSearch.aspx\#? auth\% 3dAggarwal\%2bAND\%2bBharat\%2bB (accessed 24 February, 2020).

2 Quack Watch: https://www.quackwatch.org/11Ind/ (accessed 24 February, 2020).

\section{References}

Ackerman T (2016) M.D. Anderson scientist, accused of manipulating data, retires. Houson Chronicle

Attorney General of the State of New York Health Care Bureau (2014) Assurance of discontinuance under executive law section 63, Subdivision 15 Assurance No 14-222

Brouns FJPH, van Buul VJ, Shewry PR (2013) Does wheat make us fat and sick? J Cereal Sci 58(2):209-215

Casazza K, Fontaine KR, Astrup A et al. (2013) Myths, presumptions, and facts about obesity. N. Engl J Med 368(5):446-454

Department of Justice (2013) Weight-loss infomercial Pitch-Man Kevin Trudeau convicted of criminal contempt. U.S. Attorney's Office Northern District of Illinois

Goff SL, Foody JM, Inzucchi S et al. (2006) Brief report: nutrition and weight loss information in a popular diet book: is it fact, fiction, or something in between? J Gen Intern Med 21(7):769-774

Gupta SC, Reuter S, Phromnoi K et al. (2016) Additions and corrections: Nimbolide sensitizes human colon cancer cells to TRAIL through reactive oxygen species- and ERK-dependent up-regulation of death receptors, and Bax. J Biol Chem 291(32):53

Internation Food Information Council Foundation (2018) 2018 Food \& Health Survey. Foodinsight.org

Ioannidis JPA (2018) The challenge of reforming nutritional epidemiologic research. JAMA 320(10):969-970

Kannappan R, Yadav VR, Aggarwal B (2016) Additions and corrections: $\gamma$-Tocotrienol but not $\gamma$-tocopherol blocks STAT3 cell signaling pathway through induction of protein-tyrosine phosphatase SHP-1 and sensitizes tumor cells to chemotherapeutic agents. J Biol Chem 291(32):16922

Levinovitz A (2015) The problem with David Perlmutter, the Grain Brain Doctor. The Cut

MacIntire SJ (2006) Warning letter CHI-7-06. Department of Health and Human Services, Chicago District

Nutrisytem (2015) Nutrisystem, Inc. acquires south beach diet brand from SBD holdings group corp. Nutrisystem News Room

Nutrisystem (2018) Nutrisystem announces third quarter 2018 financial results. Business Wire

Penketh A (2014) Dukan diet creator struck off French medical register. The Guardian

Prasad S, Yadav VR, Sundaram C et al. (2016a) Additions and corrections: Crotepoxide chemosensitizes tumor cells through inhibition of expression of proliferation, invasion, and angiogenic proteins linked to proinflammatory pathway. J Biol Chem 291(32):16921

Prasad S, Yadav VR, Kannappan R (2016b) Additions and corrections: Ursolic acid, a pentacyclin triterpene, potentiates TRAIL-induced apoptosis through p53-independent up-regulation of death receptors. J Biol Chem 291 (32):16924

Sung B, Park B, Yadav VR et al. (2016a) Additions and corrections: Celastrol, a triterpene, enhances TRAIL-induced apoptosis through the down-regulation of cell survival proteins and up-regulation of death receptors. J Biol Chem 291(32): 16920

Sung B, Ravindran J, Prasad S et al. (2016b) Additions and corrections: Gossypol induces death receptor-5 through activation of ROS-ERK-CHOP pathway and sensitizes colon cancer cells to TRAIL. J Biol Chem 291(32):16923

U.S. Department of Health and Human Services and U.S. Department of Agriculture (2015) 2015-2020 Dietary Guidelines for Americans. http://health. gov/dietaryguidlines/2015/guidelines/

Walker SJ (2005) Warning letter ref. no. CL-04-HFS-810-134. Department of Health and Human Services, College Park, MD

Yucesoy B, Wang X, Huang J et al. (2018) Success in books: a big data approach to bestsellers. EPJ Data Science 7(1):1-25

\section{Author contributions}

Contributors and sources: RMM and JPAI performed data collection, conceptualized, and drafted the first version. XW and A-LB obtained the database of nutritional bestsellers. RMM, JPAI, XW, and A-LB revised and contributed to subsequent drafts. 


\section{Competing interests}

The authors declare no competing interests.

\section{Additional information}

Supplementary information is available for this paper at https://doi.org/10.1057/s41599 020-0415-6.

Correspondence and requests for materials should be addressed to J.P.A.I.

Reprints and permission information is available at http://www.nature.com/reprints

Publisher's note Springer Nature remains neutral with regard to jurisdictional claims in published maps and institutional affiliations. (c) (i) Open Access This article is licensed under a Creative Commons Attribution 4.0 International License, which permits use, sharing, adaptation, distribution and reproduction in any medium or format, as long as you give appropriate credit to the original author(s) and the source, provide a link to the Creative Commons license, and indicate if changes were made. The images or other third party material in this article are included in the article's Creative Commons license, unless indicated otherwise in a credit line to the material. If material is not included in the article's Creative Commons license and your intended use is not permitted by statutory regulation or exceeds the permitted use, you will need to obtain permission directly from the copyright holder. To view a copy of this license, visit http://creativecommons.org/ licenses/by/4.0/.

(C) The Author(s) 2020 